\title{
UV-Photolysis of S-(cis-1-Propenyl)-L-cysteine in Oxygen-free Aqueous Solution ${ }^{\dagger}$
}

\author{
Takashi Hanzawa, Hiroyuki Nishimura and Junya Mizutani \\ Department of Agricultural Chemistry, Faculty of Agriculture, Hokkaido University, Sapporo, Japan
}

Received June 9, 1973

\begin{abstract}
From the comparisons of mass spectral fragmentations and gas chromatographic retention times with reference compounds, volatile flavor products from UV-photolysis of S-(cis-1propenyl)-L-cysteine in oxygen-free aqueous solutions were identical with propanal, 2-methyl2-pentenal, $n$-propyl mercaptan, allyl mercaptan, 1-propenyl mercaptan, 2-methylthiophene, 3-methylthiophene, 2,3-dimethylthiophene, 2,4-dimethylthiophene, 2,5-dimethylthiophene, 3,4-dimethylthiophene, $n$-propyl 1-propenyl sulfide and di-1-propenyl sulfide. Moreover, from the comparison of two-dimentional thin-layer chromatograms with reference compounds, ninhydrin-positive products with interest in terms of the degradation mechanism were identical with alanine and cystine. It seems that above-mentioned thiophene derivatives are produced via 1-propenyl thiyl radicals.
\end{abstract}

Sulfur-containing amino acids in food are known to be highly sensitive to UV-and $\gamma$ irradiation. The changes in sulfur compounds are generally assumed to contribute significantly to the characteristic off-flavor.

In connection with food-flavor deterioration accompanied by irradiation, the authors have investigated the formation mechanism of the degradation products from sulfur-containing amino acids (precursors of onion and garlic flavor) irradiated by $\gamma$-rays in oxygen-free aqueous solutions., ${ }^{2,3)}$ Recently, a new cistrans isomerization has been found during the studies on $\gamma$-radiolysis of S-(cis-1-propenyl)-Lcysteine (1) and its sulfoxide (2), and it has been elucidated that several cis or trans-1propenyl sulfide $(\mathbf{3}, \mathbf{4})$ as the major products are produced via 1-propenyl thiyl radicals., ${ }^{4,5}$
In these connections, UV-photolysis of S(cis-1-propenyl)-L-cysteine (one of the naturally-occurring lachrymatory precursors of onion) in aqueous solution is interested in terms of the deterioration of food flavor and organic reactions.

In this paper the authors deal with the idenfication of products from S-(cis-1-propenyl)L-cysteine irradiated by UV-ray in oxygen-free aqueous solution.

\section{MATERIALS AND METHODS}

$S$-(cis-1-Propenyl)-L-cysteine (PeCS). This compound was prepared by the synthetic procedure of Carson and Wong ${ }^{6 !}$ from S-allyl-L-cysteine, which had been synthesized by a modification of the method of du Vigneaud et al.," with potassium tert-butoxide in dimethyl sulfoxide: $\mathrm{mp} 179 \sim 180^{\circ} \mathrm{C}$ (dec.):

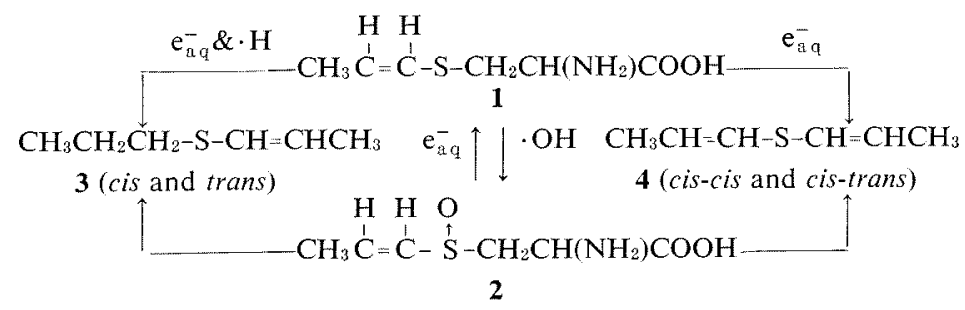

+ Studies on $\gamma$-Radiolysis of Sulfur-containing Amino Acids. Part VI. See Preliminary Communications. ${ }^{11}$ A part of this work was presented at the Annual Meeting of the Agricultural Chemical Society of Japan, in Tokyo, April, 1973. 
$\mathrm{IR} \nu_{\mathrm{max}}^{\mathrm{KBr}} \mathrm{cm}^{-1}: 2970,2840,2580,2100,\left(\mathrm{NH}_{3}{ }^{+}\right), 1580$ $\left(\mathrm{COO}^{-}\right)$, no absorption at 990 and $918 \mathrm{~cm}^{-1}$ (allyl double bond) and at $967 \mathrm{~cm}^{-1}$ (trans isomer); NMR $\left(\mathrm{D}_{2} \mathrm{O}-\mathrm{NaOD}\right) \delta: 5.96(1 \mathrm{H}$, doublet, $J=9 \mathrm{~Hz}$, cis configuration of the double bond); MS $m / e ; 161{\left(\mathrm{M}^{+}\right) \text {, }}^{+}$ $116\left(\mathrm{M}^{+}-\mathrm{COOH}\right), 88\left(\mathrm{CH}_{3} \mathrm{CH}=\mathrm{CHS}^{+} \mathrm{CH}_{3}\right), 87\left(\mathrm{CH}_{3}-\right.$ $\mathrm{CH}=\mathrm{CHS} \stackrel{+}{=} \mathrm{CH}_{2}$, base peak $), 74\left(\mathrm{H}_{2} \stackrel{+}{\mathrm{N}}=\mathrm{CHCOOH}\right)$ $41\left(\mathrm{CH}_{3} \mathrm{CH}=\mathrm{CH}^{+}\right), 39\left(\mathrm{C}_{3} \mathrm{H}_{3}{ }^{+}\right)$. Anal. Found: $\mathrm{C}$, $44.70 ; \mathrm{H}, 6.81 ; \mathrm{N}, 8.66$. Calcd. for $\mathrm{C}_{6} \mathrm{H}_{11} \mathrm{NO}_{2} \mathrm{~S}$ : C, $44.72 ; \mathrm{H}, 6.88 ; \mathrm{N}, 8.69 \%$.

$U V$-Photolysis. An oxygen-free neutral solution of PeCS (20 mM) dissolved in triply distilled water was placed in a stoppered quartz tube and irradiated for $20 \mathrm{hr}$ at room temperature using a $50 \mathrm{~W}$ low pressure mercury lamp, Ushio UL1-5BQ (2537 $)$.

Separation and identification of photoproducts. Volatile flavor products from irradiated PeCS (2 liters of solution) were distilled off by passing through nitrogen gas as a carrier at approximately $80^{\circ} \mathrm{C}$, and absorbed into about $5 \mathrm{ml}$ of an isopentane trap cooled with dry ice-ethanol. The method of GC-MS combination was used to characterize the volatile products, and further the products were confirmed by comparing with the gas chromatograms and mass spectra of respective reference compounds. A Watson-Biemann helium separator ${ }^{8}$ was used between the gas chromatograph (Hitachi Model K-53 gas chromatograph) and the mass spectrometer (Hitachi Model RMS-4 mass spectrometer). The operating parameters were as follows. Gas chromatograph: Column, a stainless steel column, $1 \mathrm{~m} \times 3 \mathrm{~mm}$ i.d. packed with $20 \%$ Reoplex 400 on 60 to 80 mesh acid-washed C-22; flow rate, helium carrier gas at $25 \mathrm{ml} / \mathrm{min}$; temperature, $80^{\circ} \mathrm{C}$; injection port temperaure, $150^{\circ} \mathrm{C}$. Mass spectrometer: Ion source temperature, $200^{\circ} \mathrm{C}$, ion source pressure, $2 \times 10^{-6} \mathrm{mmHg}$; target current $60 \mu \mathrm{A}$; total emission, $80 \mu \mathrm{A}$; ionization potential, $80 \mathrm{eV}$.

Two-dimentional thin-layer chromatography of ninhydrin-positive products from irradiated PeCS was carried out on Avicel by using (i) $n$-butanolacetic acid-water $(4: 1: 1, v / v)$ and phenol-water $(4: 1, v / v)$ or (ii) $n$-butanol-acetic acid-water $(63: 10$ : $27, \mathrm{v} / \mathrm{v})$ and phenol-acetic acid-water $(7: 1: 2, \mathrm{v} / \mathrm{v})$ as solvent systems and the chromatograms were colored with ninhydrin reagent.

\section{Synthesis of authentic thiophene derivatives.}

a) 2-Methylthiophene. A mixture of levulinic acid $(25 \mathrm{~g}, 0.215$ mole) and phosphorus trisulfide $(22 \mathrm{~g}, 0.139$ mole) was heated. A vigorous reaction took place; as soon as the reaction had subsided, the product was distilled from the reaction mixture. The crude distillate was purified by using the preparative gas chromatograph (Varian Model 90 P). 2-Methylthiophene had bp $112 \sim 113^{\circ} \mathrm{C}$ and the yield was $14.2 \%$. (lit. ${ }^{9)} 15 \%$ ); IR $\nu_{\max }^{\mathrm{fl} 1 \mathrm{~m}} \mathrm{~cm}^{-1}: 845,815,750$ (thiophene ring); NMR $\left(\mathrm{CCl}_{4}\right) \delta: 2.47(3 \mathrm{H}, \mathrm{s}), 6.72(1 \mathrm{H}, \mathrm{m}) .6 .85$ $(1 \mathrm{H}, \mathrm{dd}), 7.02(1 \mathrm{H}, \mathrm{dd}) ; \mathrm{MS} m / e ; 98\left(\mathrm{M}^{+}\right), 97\left(\stackrel{+}{\mathrm{M}^{+} \mathrm{H}}\right.$, base peak), $59\left(\mathrm{CH}_{3} \mathrm{C} \equiv \mathrm{S}^{+}\right), 45\left(\mathrm{HC} \equiv \mathrm{S}^{+}\right)$. Anal. Found: $\mathrm{C}, 61.41 ; \mathrm{H}, 6.39 ; \mathrm{S}, 32.14$. Calcd. for $\mathrm{C}_{5} \mathrm{H}_{6} \mathrm{~S}$ : C, $61.23 ; \mathrm{H}, 6.12 ; \mathrm{S}, 32.65 \%$.

b) 3-Methylthiophene. It was obtained as a byproduct in preparation of 2,4- or 3,4-dimethylthiophene. 3-Methylthiophene was purified by using the gas chromatograph. IR $\nu_{\mathrm{m} \otimes \mathrm{X}}^{\mathrm{film}} \mathrm{cm}^{-1}: 850,760$ (thiophene ring); NMR $\left(\mathrm{CCl}_{4}\right) \delta: 2.19(3 \mathrm{H}, \mathrm{s}), 6.68(1 \mathrm{H}, \mathrm{d}), 6.73(1 \mathrm{H}, \mathrm{s})$, $7.02(1 \mathrm{H}, \mathrm{d})$; MS m/e: $98\left(\mathrm{M}^{+}\right), 97\left(\mathrm{M}^{+}-\mathrm{H}\right.$, base peak), $59\left(\mathrm{CH}_{3} \mathrm{CH} \equiv \mathrm{S}^{+}\right), 45\left(\mathrm{HC} \equiv \mathrm{S}^{+}\right)$.

c) 2,5-Dimethylthiophene. A mixture of acetonylacetone $(25 \mathrm{~g}, 0.219$ mole $)$ and phosphorus trisulfide (22 g, 0.139 mole) was heated for one hr. The product was distilled from the reaction mixture and purified by using the gas chromatograph. 2,5-Dimethylthiophene had bp $134 \sim 135^{\circ} \mathrm{C}$ and the yield was about $50 \%$ (lit. $101 \quad 50 \sim 60 \%$ ); IR $\nu_{\max }^{\text {film }} \mathrm{cm}^{-1}$ : 790 (thiophene ring); NMR $\left(\mathrm{CCl}_{4}\right) \tilde{\delta}: 2.37(6 \mathrm{H}, \mathrm{s})$, $6.40(2 \mathrm{H}, \mathrm{s})$; MS m/e: $112\left(\mathrm{M}^{+}\right), 111\left(\mathrm{M}^{+}-\mathrm{H}\right.$, base peak), $97\left(\mathrm{M}^{+}-\mathrm{CH}_{3}\right), 59\left(\mathrm{CH}_{3} \mathrm{C} \equiv \mathrm{S}^{+}\right), 45\left(\mathrm{HC} \equiv \mathrm{S}^{+}\right)$. Anal. Found: C, 64.73; H, 7.22; S, 27.48. Calcd. for $\mathrm{C}_{6} \mathrm{H}_{8} \mathrm{~S}: \mathrm{C}, 64.27 ; \mathrm{H}, 7.19 ; \mathrm{S}, 28.54 \%$.

d) 2,4-Dimethylthiophene. Condensation of ethyl acetoacetate and ethyl2-bromopropionate afforded diethyl 2-methyl-3-carboxylevulinate, bp $123^{\circ} \mathrm{C} /$ $6 \mathrm{mmHg}(52 \%) ; \mathrm{IR} \nu_{\max }^{\mathrm{film}} \mathrm{cm}^{-1}: 1735$ (ester), $1715(\mathrm{CO})$. Hydrolysis of this ester with concentrated hydrochloric acid gave 2-methyllevulinic acid; $\operatorname{IR} \nu_{\max }^{\mathrm{flm}} \mathrm{cm}^{-1}$ : $1715(\mathrm{CO}), 1710(\mathrm{COOH})$. A mixture of 2-methyllevulinic acid $(24 \mathrm{~g}, 0.185 \mathrm{~mole})$ and phosphorus. trisulfide (22 $\mathrm{g}, 0.139$ mole) was heated in carbon dioxide atmosphere. The product was distilled from the reaction mixture and was purified by using the gas chromatograph. 2,4-Dimethylthiophene had bp $137 \sim 138^{\circ} \mathrm{C}$ and the yield was $33.8 \%$ (lit. $23 \%$, ${ }^{111}$ $34 \%$ \% NMR $\left(\mathrm{CCl}_{4}\right) \delta: 2.17(3 \mathrm{H}, \mathrm{s}), 2.42(3 \mathrm{H}, \mathrm{s}), 6.45(1 \mathrm{H}$, s), $6.52(1 \mathrm{H}, \mathrm{m})$; $\mathrm{MS} m / e: 112\left(\mathrm{M}^{+}\right), 111\left(\mathrm{M}^{+}-\mathrm{H}\right.$, base peak), $97\left(\mathrm{M}^{+}-\mathrm{CH}_{3}\right), 59\left(\mathrm{CH}_{3} \mathrm{C} \equiv \mathrm{S}^{+}\right), 45(\mathrm{CH} \equiv$ $\left.\mathrm{S}^{+}\right)$. Anal. Found: $\mathrm{C}, 64.15 ; \mathrm{H}, 7.23 ; \mathrm{S}, 27.66$. Calcd. for $\mathrm{C}_{6} \mathrm{H}_{8} \mathrm{~S}: \mathrm{C}, 64.27 ; \mathrm{H}, 7.19 ; \mathrm{S}, 28.54 \%$.

e) 2,3-Dimethylthiophene. Condensation of ethyl 2-methyl-acetoacetate and ethyl bromoacetate afforded diethyl 3-melthyl-3-carboxylevulinate, bp $102^{\circ} \mathrm{C} / 3 \mathrm{mmHg}(50 \%)$. Hydrolysis with concentrated hydrochloric acid gave 3-methylleuvulinic acid. A mixture of 3-methyllevulinic acid $(18 \mathrm{~g}, 0.139$ mole) 
and phosphorus trisulfide $(15 \mathrm{~g}, 0.094 \mathrm{~mole})$ was heated for one hour and the product was distilled from the reaction mixture. The yield was about $3 \%$ (lit. ${ }^{13,14)} 20 \%$ ). MS m/e: $112\left(\mathrm{M}^{+} \cdot\right), 111\left(\mathrm{M}^{+}-\mathrm{H}\right)$, $97\left(\mathrm{M}^{+}-\mathrm{CH}_{3}\right.$, base peak $), 59\left(\mathrm{CH}_{3} \mathrm{C} \equiv \mathrm{S}^{+}\right), 45(\mathrm{HC} \equiv$ $\left.\mathrm{S}^{+}\right)^{15)}$

f) 3,4-Dimethylthiophene. Condensation of ethyl 2-bromopropionate and ethyl 2-cyanopropionate afforded diethyl 2,3-dimethyl-2-cyanosuccinate, bp $125^{\circ} \mathrm{C} / 6 \mathrm{mmHg} \quad(66 \%) ; \quad I R \nu_{\max }^{\mathrm{film}} \mathrm{cm}^{-1}: 2300$ (CN), 1736 (ester). Hydrolysis of this ester with $6 \mathrm{~N}$ hydrochloric acid gave 2,3-dimethylsuccinic acid as a crystal, mp $191.2^{\circ} \mathrm{C}$. A mixture of the sodium salt of 2,3dimethylsuccinic acid ( $19 \mathrm{~g}, 0.100$ mole) and phosphorus trifulfide ( $19 \mathrm{~g}, 0.120$ mole) was subjected to dry distillation in a stream of carbon dioxide. The crude distillate was purified by using the gas chromatograph. 3,4-Dimethylthiophene had bp $144 \sim 146^{\circ} \mathrm{C}$ and the yield was $26.8 \%$ (lit. $\left.21 \sim 22 \%{ }^{16)} 43 \%{ }^{171}\right)$; IR $\nu_{\max }^{\text {fl } \mathrm{cm}^{-1}}$ 860,780 (thiophene ring); NMR $\left(\mathrm{CCl}_{4}\right) \delta: 2.13(6 \mathrm{H}, \mathrm{s})$, $6.77(2 \mathrm{H}, \mathrm{s})$; MS m/e: $112\left(\mathrm{M}^{+}\right), 111\left(\mathrm{M}^{+}-\mathrm{H}\right.$, base peak), $97\left(\mathrm{M}^{+}-\mathrm{CH}_{3}\right), 59\left(\mathrm{CH}_{3} \mathrm{C} \equiv \mathrm{S}^{+}\right), 45\left(\mathrm{HC} \equiv \mathrm{S}^{+}\right)$. Anal. Found: C, $64.56 ; \mathrm{H}, 7.54 ; \mathrm{S}, 27.85$. Calcd. for $\mathrm{C}_{6} \mathrm{H}_{8} \mathrm{~S}: \mathrm{C}, 64.27 ; \mathrm{H}, 7.19 ; \mathrm{S}, 28.54 \%$.

\section{RESULTS AND DISCUSSION}

The gas chromatogram of volatile products from irradiated S-(cis-1-propenyl)-L-cysteine (PeCS) is shown in Fig. 1.

Mass spectra of main peaks from irradiated

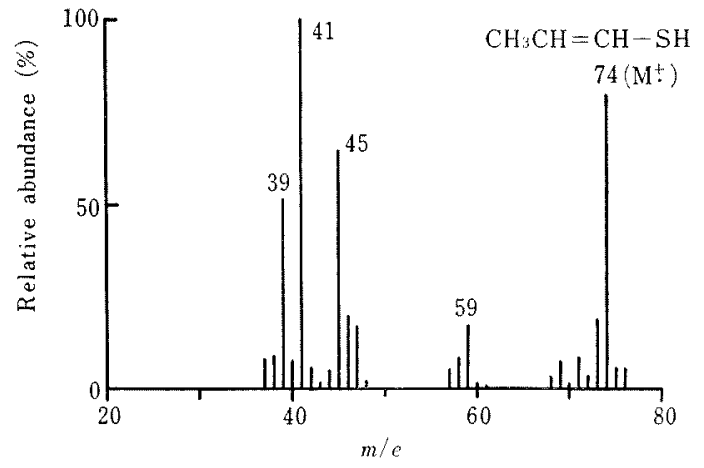

FIG. 2. Mass Spectrum of Peak 4.

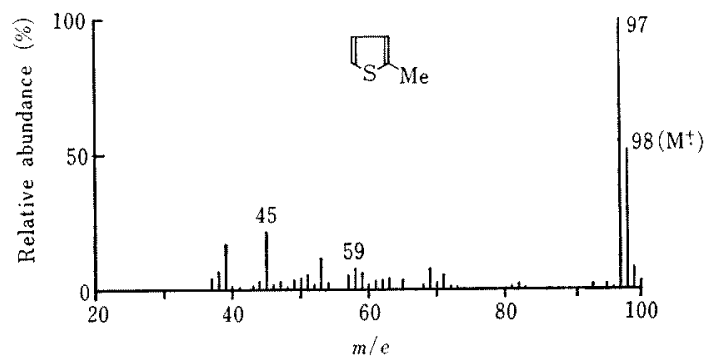

Fig. 3. Mass Spectrum of Peak 5.

PeCS are shown in Figs. 2 to 8. Moreover, from the comparisons of gas chromatographic retention time and mass spectrometric frag-

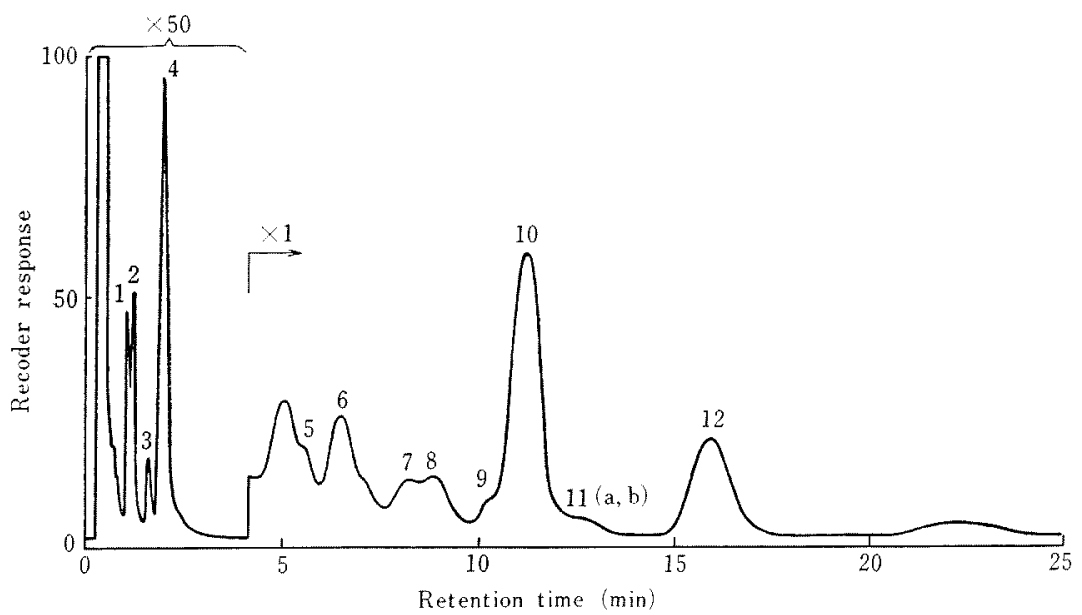

FIG. 1. Gas Chromatogram of Head Space Vapor from S-(cis-1-Propenyl)-L-cysteine Irradiated by UVRay in Oxygen-free Aqueous Solution.

Column: $20 \%$ Reoplex $400(1 \mathrm{~m} \times 3 \mathrm{~mm})$ coated on $60 \sim 80$ mesh $\mathrm{C}-22$. Temperature $80^{\circ} \mathrm{C}$. Hitachi Model K-53 (FID), attenuation $\times 50(0 \sim 4.3 \mathrm{~min}) \sim \times 1(4.3 \sim 25 \mathrm{~min})$. 


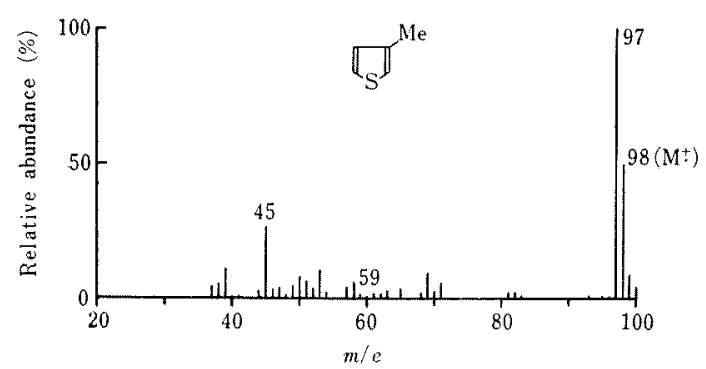

FIG. 4. Mass Spectrum of Peak 6.

Table I. Identification of Volatile ComPOUNDS FROM S-(cis-1-PROPENYL)-L-CYSTEINE IRRADIATED BY UV-RAY

Peak no.

1 Propanal

2 -Propyl mercaptan

3 Allyl mercaptan

4 1-Propenyl mercaptan

5 2-Methylthiophene

6 3-Methylthiophene

7 n-Propyl 1-propenyl sulfide

8 2,5-Dimethylthiophene

9 2-Methyl-2-pentenal

10 2,4-Dimethylthiophene

11 a) Di-1-propenyl sulfide and b) 2,3-Dimethylthiophene

12 3,4-Dimethylthiophene mentations with reference compounds, the volatile compounds were identified as shown in Table I.

The mass spectral fragmentation of 1propenyl mercaptan (Fig. 2) has been rationalized on the basis of the metastable ion peaks and distinguished from allyl mercaptan. ${ }^{18}$ In Figs. 3 , and 4 , the relative abundance of a fragment, mass $59\left(\mathrm{CH}_{3} \mathrm{C} \equiv \mathrm{S}^{+}\right)$explain a remarkable difference between 2-methylthiophene and 3-methylthiophene; the small peak, mass 59 from 3-methylthiophene $\left(\mathrm{M}^{+} 98\right)$ must have been produced through methyl scrambling on the thiophene ring. Though the base peak of mass spectra of mono- and dimethylthiophenes usually is (M-1) ion, only that of 2,3-dimethylthiophene is mass 97 $\left(\mathrm{M}^{+}-15\right)$ as shown in Fig. 7. In addition, the remarkable difference of the spectral fragmentation among 2,5-, 2,4- and 3,4dimethylthiophene, whose spectra are shown in Figs. 5, 6 and 8, respectively, is mass 59 as well as monomethylthiophenes; the mass 59 peak is large (over $15 \%$ of the base peak) when methyl

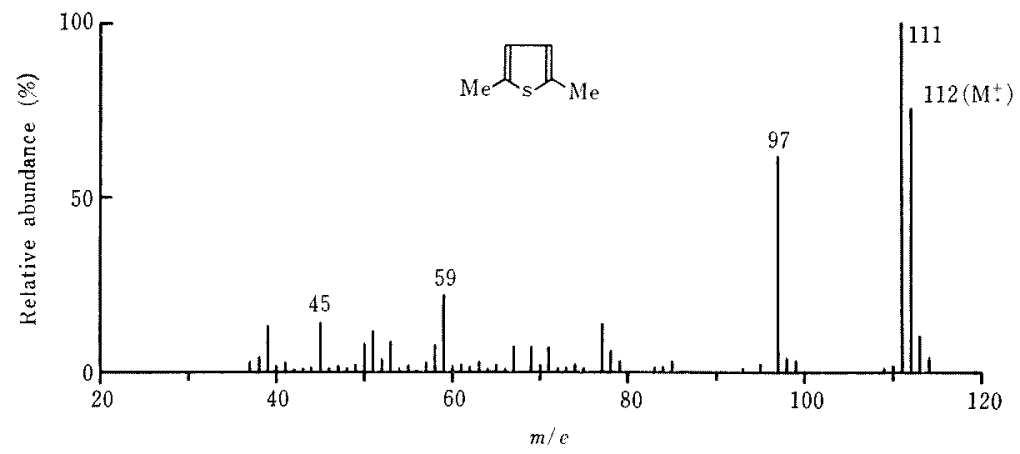

FIG. 5. Mass Spectrum of Peak 8.

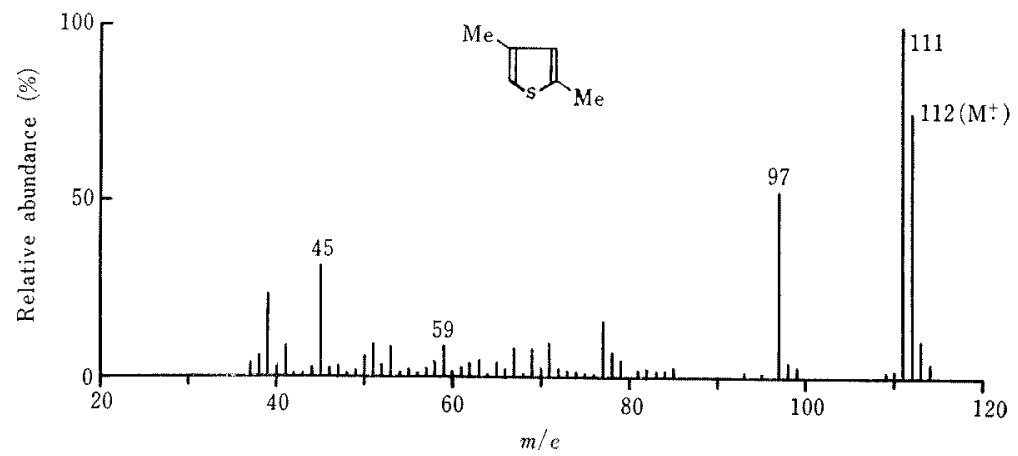

FIG. 6. Mass Spectrum of Peak 10. 


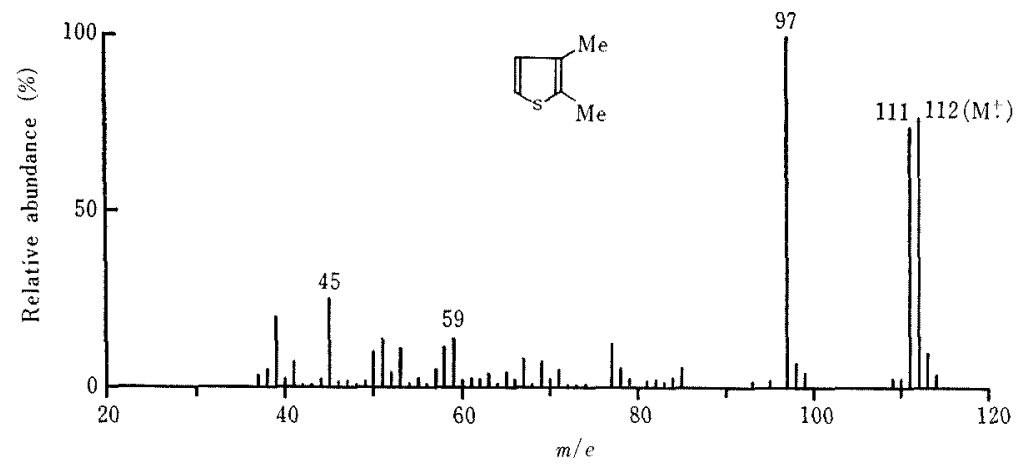

Fio. 7. Mass Spectrum of Peak 11 (b).

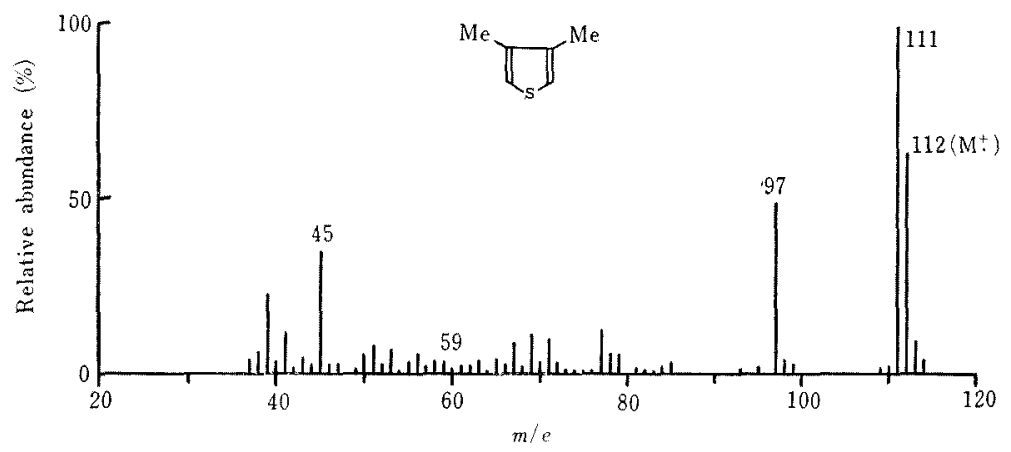

Fig. 8. Mass Spectrum of Peak 12.

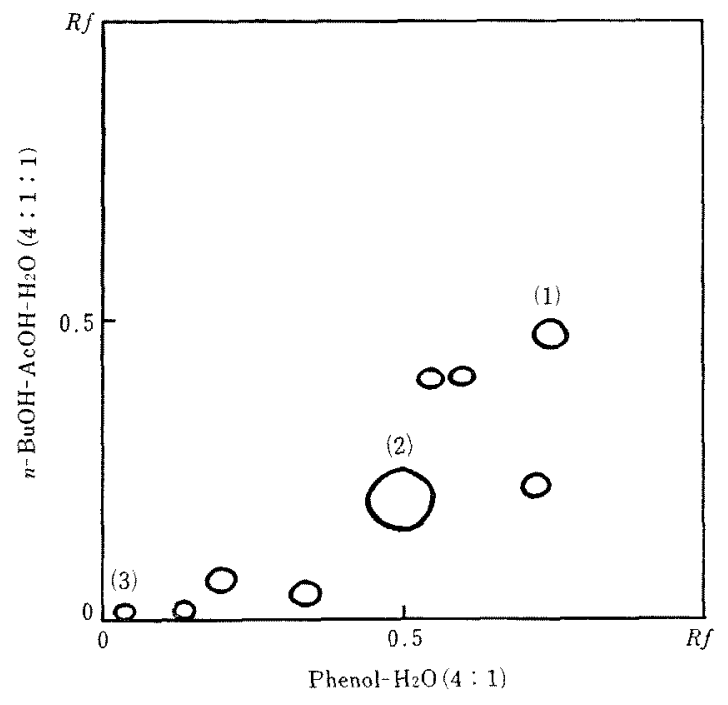

FIG. 9. Thin-layer Chromatogram of S-(cis-1-Propenyl)-L-cysteine Irradiated by UV-Ray in Oxygen-free Aqueous Solution.
(1) S-(cis-1-Propenyl)-L-cysteine
(2) Alanine (3) Cystine

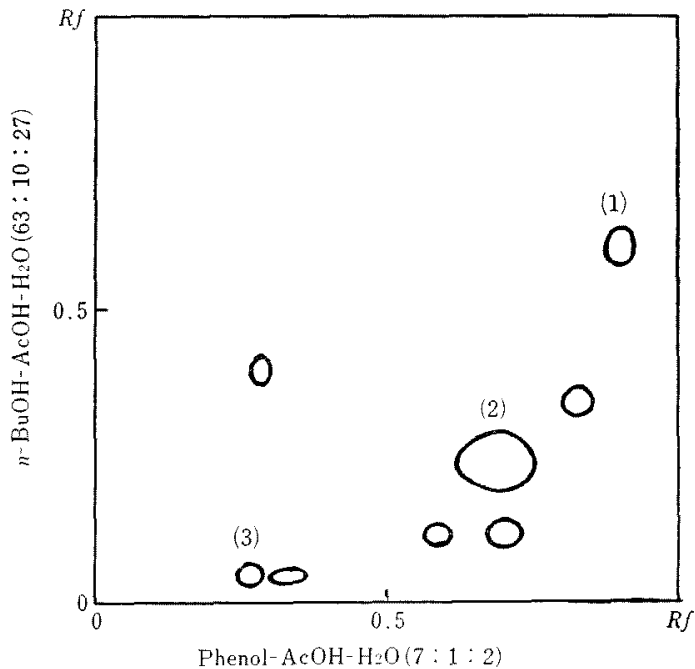

FIG. 10. Thin-layer Chromatogram of S-(cis-1Propenyl)-L-cysteine Irradiated by UV-Ray in Oxygenfree Aqueous Solution.
(1) S-(cis-1-Propenyl)-L-cysteine
(2) Alanine
(3) Cystine 
groups are in both the 2-and 5-positions, intermediate when a methyl group is in the 2-position and small (less than $5 \%$ of the base peak) when both the 2- and 5-positions are unoccupied. ${ }^{15}$,

The major products from UV-photolysis of PeCS are remarkably different from $\gamma$-radiolysis in contrast to the case of S- $n$-propyl- or Sallyl-L-cysteine, as di-n-propyl sulfide and di-n-propyl disulfide are produced from S- $n$ propyl-L-cysteine, and diallyl sulfide, n-propyl allyl sulfide and allyl alcohol are produced from S-allyl-L-cysteine by UV- or $\gamma$-irradiation. Moreover, in the case of $\gamma$-irradiation $\left(10^{4} \sim\right.$ $10^{6} \mathrm{rad}$ ), thiophene derivatives could not be detected even by using the high sensitive gas chromatograph. Among thiophene derivatives produced from UV-irradiated PeCS, 3methylthiophene, 2,4- and 3,4-dimethylthiophenes are major products, and 2-methylthiophene, 2,5-and 2,3-dimethylthiophene are minor products.

Figures 9 and 10 show the two-dimentional thin-layer chromatograms of the ninhydrin positive products from UV-irradiated PeCS. Among these products, alanine (large) and cystine (trace) from PeCS were identified by

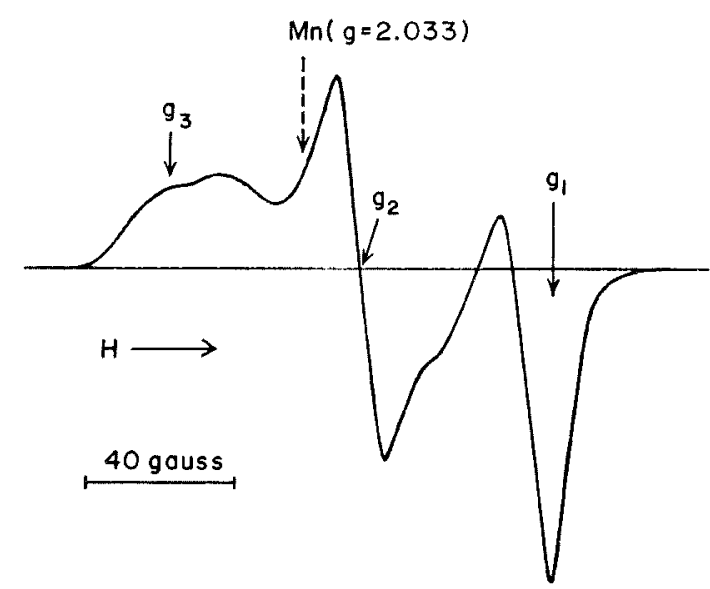

FIG. 11. Electron Spin Resonance Spectrum of S-(cis-1-Propenyl)-L-cysteine Irradiated in Oxygenfree Aqueous Solution at $77^{\circ} \mathrm{K}$. The spectrum was recorded in $8 \mathrm{hr}$ after irradiation for $10 \mathrm{hr}(20 \mathrm{~mm}$,

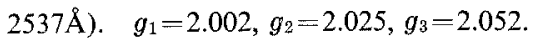

comparison of their $R f$ values with those of authentic samples. As alanine was largely produced even at the early stage of UVirradiation, it seems that PeCS is cleaved to give 1-propenyl thiyl radical and 2-amino-2carboxyethyl radical in the initiation step. Moreover, from the measurement of the ESR spectrum $\left(77^{\circ} \mathrm{K}\right)$ of PeCS irradiated in aqueous system, the anisotropic signal $\left(\mathrm{g}_{1}=2.002\right.$, $\mathrm{g}_{2}=2.025, \mathrm{~g}_{3}=2.052$ ) was observed as shown in Fig. 11 and the signal showed a typical thiyl radical which agreed well with reference alkylthiyl radicals. ${ }^{19)}$ From above-mentioned results, thiophene derivatives must be produced via 1-propenyl thiyl radicals. Further detailed mechanism will be presented elsewhere.

\section{REFERENCES}

1) H. Nishimura, T. Hanzawa and J. Mizutani, Tetrahedron Letters, 1973, 343.

2) H. Nishimura, S. Kawakishi and M. Namiki, Agr. Biol. Chem., 34, 609 (1970).

3) H. Nishimura, J. Mizutani, Y. Obata and $\mathbf{M}$. Namiki, Tetrahedron, 27, 307 (1971).

4) H. Nishimura and J. Mizutani, J. C. S. Chem. Comm., 1972, 738

5) H. Nishimura and J. Mizutani, Agr. Biol. Chem., 37, 213 (1973).

6) J. F. Carson and F. F. Wong, Chem. Ind. (London), 1963, 1764.

7) V. du Vigneaud, H. S. Loring and H. A. Craft, J. Biol. Chem., 105, 481 (1934).

8) J. T. Watson and K. Biemann, Anal. Chem., 37, 844 (1965).

9) W. Kues and C. Paal, Ber., 19, 555 (1886).

10) C. Paal, ibid., 18, 2251 (1885).

11) N. Zelinsky, ibid., 20, 2017 (1887).

12) I. J. Rinkes, Rec. Trav. Chim., 52, 1052 (1933).

13) C. Paal and A. Püschel, Ber, 20, 2557 (1887).

14) W. Grünewald, ibid,, 20, 2585 (1887).

15) I. W. Kinney, Jr. and G. L. Cook, Anal. Chem., 24, 1391 (1952).

16) N. Zelinsky, Ber., 21, 1835 (1888).

17) R. P. Linstead, E. G. Noble and J. M. Wright, J. Chem. Soc., 1937, 911.

18) H. Nishimura, S. Koike and J. Mizutani, Agr. Biol. Chem., 37, 1219 (1973).

19) T. Henriksen and T. Sanner, Acta Chem. Scand., 20, 2888 (1966). 